\title{
E-learning multimedia applications: Towards an engineering of content creation
}

\author{
Maria Dolores Afonso Suarez, Cayetano Guerra Artal, Francisco Mario Tejera Hernandez
}

\begin{abstract}
In the same manner that e-learning applications are becoming increasingly important at the university, there are still some critical questions that should be solved with the objective of making use of the potential offered by current Web Technologies. The creation of contents that are able of capturing the attention of interest of the students and their disposal in an appropriate way constitute the main purpose of this work. The teaching content engineering expounded shows the different stages that should form part of the process. A development team, composed of different professional profiles, will work together with the lecturers of the subject to which the contents are been created, i.e. multimedia videos and interactive applications. This process should be developed according to a methodology that assure the use of appropriate resources, all that tasks -suitable of being- should be modularized and factorized. This paper presents the acquired experience in the development and use of multimedia contents for e-learning applications, created for some of the subjects of the degree in computer science engineering. The deliveries of these contents make use of Internet and video streaming techniques. The result of the work shows the students satisfaction, including their comments.
\end{abstract}

Keywords: Teaching content engineering, Didactic objectives, Active learning, Passive learning.

\section{Introduction}

During recent years University Education has experienced an important progress with respect to the resources used for lecturing. Techniques have changed from traditional blackboard methods to the use of projector transparencies (slices) and, later on, the use of video projector and PowerPoint to present the content of the lessons. Nowadays, the use of these technologies has become more common. As far as content availability for the student is concerned, it has passed from traditional notes taken in classrooms, books and photocopies to digital format of books or notes taken in classrooms, which are available in the subject's web page. In fact, the universities use to place courses on the web focusing on information delivery rather than learning. The proposal of European Higher Education Area provides the framework to take an important step forward in techniques used in lectures and in the methodology used to create them. For this reason, new methodological approaches are introduced in order to value an active learning [1] as opposed to a traditional passive learning. To value the effort that students should make in order to assimilate knowledge and not only consider the number of hours of attendance to classes. The use of e-learning techniques makes this easier; its wide range of application allows increasing education quality and delivery of information.

\section{E-learning in EHEA}

The European Higher Education Area proposes the setting up of a convergence process of educational material in Europe. New methodological approaches are introduced in order to value an active learning as opposed to a traditional passive learning. To value the effort that students should make in order to assimilate knowledge and not only consider the number of hours of attendance to classes. All this is made easier by using an e-learning [2] approach, whose extensive work field, in all range of subjects, 
allows the quality of education and its availability to increase [3]. The creation of multimedia contents for e-learning could be developed together with other European Universities, and its use could be shared within the same knowledge areas. This allows a new common line of work to be opened. It will be possible to promote European cooperation to guarantee the quality of higher education using comparable methodologies and criteria.

\section{Teaching content engineering}

We understand for that concept the whole methodological corpus that allows inserting development elearning technologies in the production of didactic solutions with appropriate invests in production time, resources and person/hour. In this manner, the creation of contents will be developed in a systematic way, planning the process and using adequate techniques. The integration of these techniques and the extent of the teaching material development project require a multidisciplinary team. This multidisciplinary team composed of a group of different professional profiles will carry out different tasks using a wide variety of technologies. These tasks will come together in order to create a production line to maximize results. The improvement of productivity and quality in teaching content creation will constitute the main objective of this engineering [4]. The proposed engineering of teaching content is carried out by means of a methodology, which divides the multimedia production process into phases and assigns tasks to each member of this professional development team. All these different phases include research on suitability of the content for e-learning, a previous analysis to select multimedia techniques to apply, the development of the contents based on the project design and, finally, the maintenance. With respect to the multidisciplinary team, it will be composed of a project manager, programmers, designers, and multimedia experts, as well as the lecturers of each subject.

\section{Methodology}

The obtaining of an optimum workflow [5] and the use of resources by the different production tasks is the main purpose of the proposed methodology. For that, we define different production phases.

\subsection{Suitability of the content for e-learning}

To create multimedia material for subjects using e-learning techniques means a considerable resource investment. Therefore, some factors, which help to make a decision about its profitability, should be taken into consideration. In this first phase a study on the suitability is made in accordance with the factors below:

The content validity. The period of time in which teaching contents do not need to be updated.

The number of students who attend classroom training. This factor takes into consideration the number of resources used in their learning.

The modularity and reusability of independently operable units, which are part of the total structure for creating more contents.

\subsection{Contents analysis}

The creation of multimedia contents is carried out through the division of teaching contents in didactic objectives. In this phase the modularization of content takes place. The extraction of the lecturers' knowledge will be necessary for the selection and proposal of different multimedia didactic elements, 
which will constitute part of these multimedia didactic units. It is recommendable to follow a methodology belonging to knowledge engineering, where the knowledge is produced according to the lecturer's subject specific knowledge, and contains the knowledge and analytical skills of one or more human experts. To achieve this aim, the tasks below are introduced:

Meetings with the lecturers. In these meetings lecturers expound the teaching objectives of the subject, explain the lesson content and the current way to portray the contents to the students.

The selection of lessons for multimedia format. The project manager, together with the lecturers, carries out the selection of lessons for which multimedia teaching content will be created

Proposal and techniques selection [6]. According to the techniques selected, and the modules repository, the project manager makes a proposal to the lecturers.

\subsection{Development}

Starting from the analysis of the previous phase, a formal design is carried out, this formal design will identify the activities and work planning that will be done under the supervision of the project manager [7]. Therefore, this phase is structured as shown below:

Formal design includes all the multimedia didactic elements to be used. In accordance with this design, both human and material resources are managed. It is a process of problem solving and planning for reaching the objectives of the project.

Development of interactive applications will follow a development methodology belonging to software engineering.

Creation of videos, for which the work will be divided into: script writing, recordings, postproduction and codification [8].

On-line disposition of multimedia contents, becoming, this way, accessible for the students.

In the process the creativity of the development team is considered fundamental.

\subsection{Maintenance}

Once the project is finished, it is difficult to assure that it will work properly unless it is tested. In order to realize a high quality solution, testing throughout each phase of the process is proposed. The project team should be involved in the maintenance phase. They are expected to work on their known issues and prepare for a new release of the created material. In order to detect defects and deficiencies in the multimedia material, some tasks are introduced:

Interviews with lecturers and students, to know first hand how they feel about this new content to use, in various aspects: accessibility, manage, design.

Questionnaires, for recover statistics results about all the aspects to be evaluated.

Comparison of academic results, where an evaluation report will be made, and academic results will be compared with those of other groups of students that have made use of traditional learning methodologies.

All these tasks will help to obtain a constructive feedback and to enhance and optimize this multimedia material and its different aspects evaluated. A thorough study of time and staff required for project development will take us to a suitable planning and this to an appropriate economic investment. Therefore, cost and resources affect directly in the amortization of the investment made for the creation of contents. 


\section{Resources}

Among the means that will be used to carry out this technology we find both human and material resources. The competences of the multidisciplinary team are defined by different profiles:

Lecturers, whose main tasks include the structure of the subject program, script writing, and the proposal and collective agreement with the project manager on the multimedia didactic units.

Project manager, who advises lecturers, coordinates efforts of the development team and assigns tasks according to the planning made.

Designers, which will carry out tasks of graphic design, user interfaces development, and 2D - 3D elements creation.

Analysts/programmers, to analyze and develop software application and programs.

Multimedia technicians, in charge of recording, editing, and postproduction.

Regarding to material resources, these are comprised of the multimedia recording studio and the laboratory room for development of software applications and editing of contents. The workstations of the editing room in the laboratory are fully equipped with the necessary computer material for creating and editing audiovisual content. Figure 1.

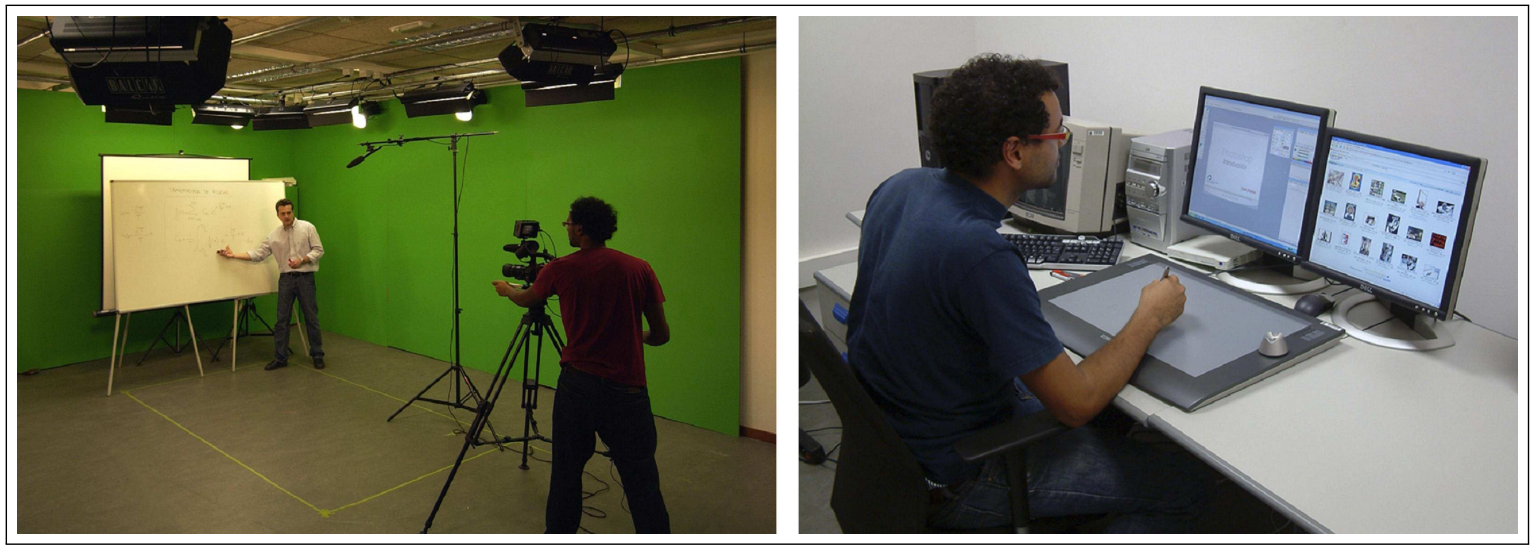

Figure 1: On the left we can observe the record Studio used for the recording of lessons. On the right workstation of the editing room.

\section{Other methodologies}

There are different strategies for the creation of teaching content for e-learning. These approaches often use a similar set of stages or phases for content development. Among them we find the "waterfall philosophy" characterized by the use of a number of phases strictly ordered in such a way that each phase begins once the previous one is finished; and the "evolutionary philosophy" or "based in prototypes", characterized by considering since the beginning that, although the project start out with a set of requirements, will arise changes in these requirements as the project is developed. However, the methodological proposal made in this work for an e-learning content engineering focuses on lecturing and this means a set of differences, related below:

Scope. Traditional methodologies are directed, generally, towards content development for corporate e-learning. The proposed methodology is focused on content development for lecturing. 
Contents modularity. In each knowledge area to create independently operable units intended for reuse in the same or a different one is proposed. This means the use of a knowledge area thorough analysis in order to make these operable units relocation possible when creating new teaching programs.

Extend of involvement. Lecturers should be part of the work team that will create multimedia contents for e-learning, should be involved not only in didactic advises tasks, according to the teaching objectives of the subject, but also should take part in the conception of the whole set of tools proposed by the project manager.

Resources. The wide variety and quantity of multimedia resources used are essential in the proposed methodology for e-learning content creation. Multimedia technology and the development of interactive applications provide suitable capabilities to develop quality contents at the university level.

\section{Lecturing experiences}

For the evaluation of e-learning techniques in lecture content, some subjects have been selected. Specifically, the subjects correspond to bachelor and graduate degrees on "Computer Science Engineering", Multimedia and Automaton Theory and Formal Languages II. Specially, the subject of Multimedia has the particular feature of covering two fundamental aspects in the teaching of computer science knowledge. On the one hand, we find purely theoretical and mathematical content which supports audio compression, image and video technologies. On the other, we find content that makes reference to the use of multimedia tools and web programming languages. In particular, the subject of Multimedia has a teaching timetable of 30 theoretical hours (twice a week), using traditional classrooms, and other 30 hours of practical lessons in the laboratory. The prepared material embraces half the timetable in the classroom. The content generated for Automaton Theory and Formal Languages II corresponds to the practical exercises of the subject. As lecturers can now count on this new multimedia teaching material, the methodology, which has been followed till now in Multimedia, has changed substantially. Firstly, the students still have the same number of learning hours; however, they receive some lessons by means of video in a dedicated server. This means that they receive, weekly, one hour in the classroom and another one through video streaming. This new material allows traditional lessons to be divided into two groups. In this way the lesson in the classroom is repeated and the student attends the most convenient classes. Therefore, not only do they not miss the opportunity to ask the lecturer doubts, but also the number of students is reduced, allowing a more personalized treatment. With respect to Automaton Theory and Formal Languages II, the prepared material only provides support to the personal training of the student. The results of this experience have been very positive. Students have valuated unanimously this new teaching model as completely recommendable. Even, the students have taken part in the improvement of the material contributing with their own ideas, needs, and wishes, like including random questions in order to implement interactivity [9]. From the valuation questionnaire issues below are recovered: Multimedia videos are very appreciated. No comments were made about accessibility or reproduction difficulties or even misunderstanding. Although students think it is necessary: the inclusion of subject's content in a pdfformat file and an index to facilitate access directly to each unit of the lesson. And just only one student pointed out that the teacher should propose more practical material in the classroom. The valuation questionnaire results are represented in the Table 1.

As we can observe, percentage for the last one question is quite good. Figure 2.

With respect to the academic efficiency revealed in the assessments, we should say that the percentage of success in the exams remains constant if we compare with the results of past years where lessons were taught in a traditional way. However, a particular fact, which is known by all lecturers when the exams' 
E-learning multimedia applications:

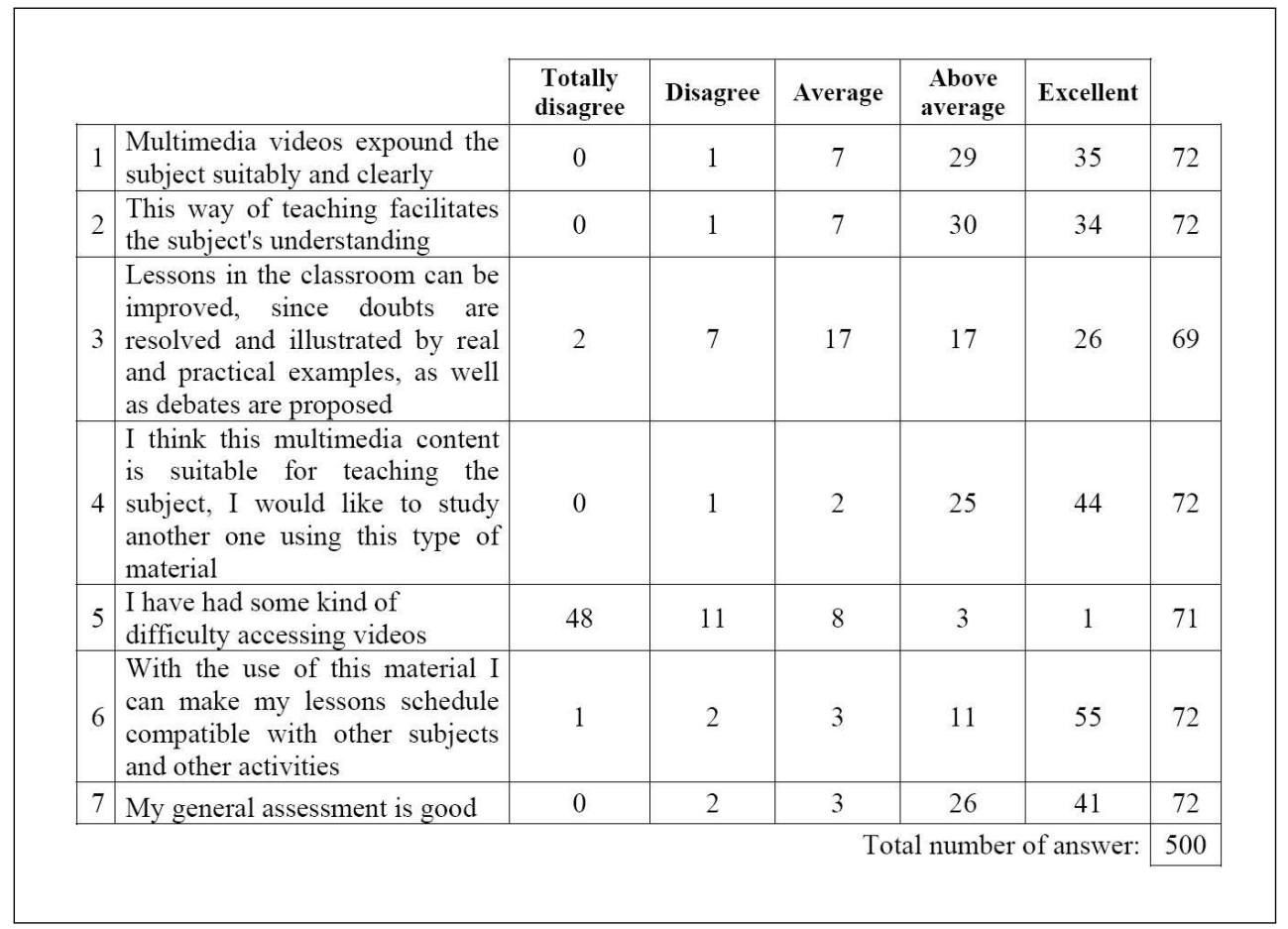

Table 1: Results from bachelor and graduate degrees on "Computer Science Engineering"

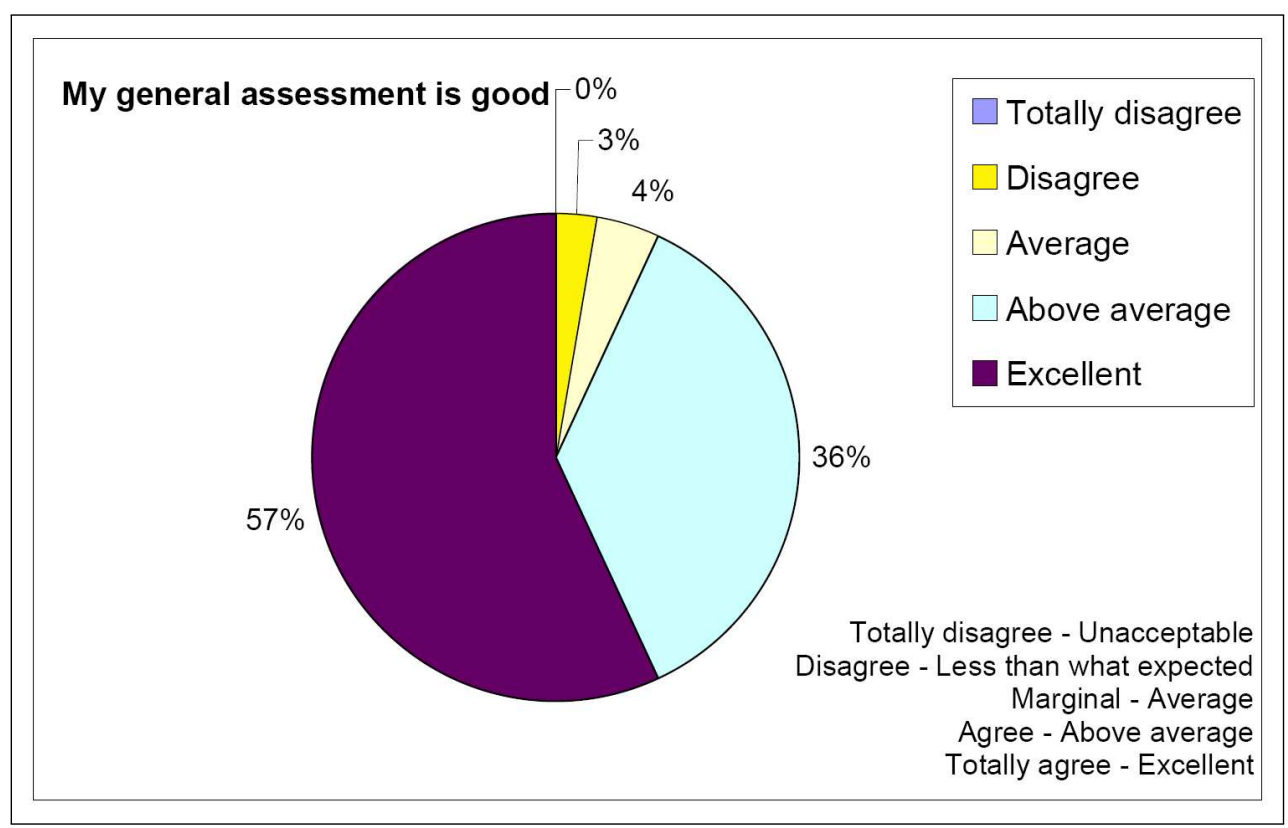

Figure 2: Graphical representation for general assessment. Results from bachelor and graduate degrees on "Computer Science Engineering" 
dates come close, should be commented. In the previous weeks to exam dates the students come more frequently, and in many cases only on those dates, to the tutorials. It is remarkable that during this teaching experience there have been practically no consultations in tutorials in all the academic year, not even on dates coming up to the exams.

\section{Future research}

The acquired experience in the development of multimedia contents for e-learning applications shows that this emergent task should be tackled through the use of a systematic, disciplined, quantifiable approach to the development, manage and maintenance of this teaching content material. In the near future, we will test the process of development of a new project from the University of Las Palmas de Gran Canaria. This project involves the creation of multimedia material for subjects of three different areas: the technical area, the health care science area, and the human, society and legal area. The election of the subjects has been made according to the factors expounded in the phase of suitability of the subject. It has been preferential for the technical department to choose subjects of the first courses of various degrees with similar contents, what implies a considerable number of lessons in common. So that, there will be subjects with the 85 or 90 per cent of their content delivered with multimedia material, which is more profitable than having only one or two subjects with the 100 per cent of the content delivered with this new material. The subject is named mathematics in some degrees and calculus in other ones. Something similar has happened in the other two knowledge areas: in the health care science area anatomy has been chosen, this is a subject of the first course of "Medical Degree" with a huge number of students. For the human, society and legal area has been chosen constitutional law, which corresponds to two different degrees: "Law" and "Economics and Business Sciences", degrees with a large number of students in the first courses too. In this way, we will delve into each phase of this new engineering focusing on improving the efficiency and cost-effectiveness of the development of multimedia contents for e-learning in these subjects selected.

\section{Conclusions}

New information technologies and e-learning will be indispensable tools in lecturing in the near future. The increasing bandwidth available for Internet connection and multimedia capacities found in current computers allow them to be used as a completely valid way for teaching. However, the lack of multimedia content production is a very important cause that limits an e-learning widespread. The creation of large-scale teaching content for lecturing needs a production methodology to assure the optimization of resources and, therefore, a reduction in costs. This work intends to contribute with the methodological lines applied in the production of multimedia teaching content for lecturing. New teaching methodologies require new teaching aims; the role of lecturers in the new educational process should be restated in the whole educational process. Lecturers should reduce the time dedicated to teaching lessons using traditional blackboard methods. This activity could be mainly, replaced by e-learning techniques. Lecturers could dedicate time to activities that offer a better quality in teaching, transmitting motivation about the subject being studied and directing the students in their studies [10]. The future of teaching in the European society should see an improvement in the quality of education, its availability, and a lower cost for students as well as for educative organizations.

\section{Acknowledgment}

We wish to thank the programm committee of ICVL 2007 that recommended the publication of an extended version of this paper. 


\section{Bibliography}

[1] A. M. Barry, Creating and Sustaining an Effective Learning Environment!. AISHE Conference 2006.

[2] http://ec.europa.eu/education/programmes/elearning/index_en.html

[3] http://ec.europa.eu/education/policies/educ/higher/higher_en.html

[4] B. Shackelford, Project Managing e-learning. ASTD. EEUU, 2002.

[5] R. Pedrosa and S. Petitz, Production of interactive contents for training in e-learning environmentsprocedures and methodologies. IADIS International Conference e-Learning 2007.

[6] W. Horton, K.Horton, E-learning tools and technologies, (1st edition), Wiley. EEUU, 2003.

[7] L. Dublin, J. Cross, Implementing E-learning. ASTD. EEUU, 2002.

[8] J. Casteleira and P. Leão, Production and distribution of contents in digital video of quality for the distance learning. IADIS International Conference e-Learning 2007.

[9] R. Rheeder, R. Diseko and G. Lautenbach, The design of interactivity for a web-based learning environment at a higher education institution. IADIS International Conference e-Learning 2007.

[10] K. Fraser, A Blended Learning Approach to Teaching "Introduction to Multimedia" - The E Bit!. AISHE Conference 2006.

Maria Dolores Afonso Suarez, Cayetano Guerra Artal Francisco Mario Hernandez Tejera Instituto Universitario de Sistemas Inteligentes y Aplicaciones Numericas en Ingenieria IUSIANI Universidad de Las Palmas de Gran Canaria Departamento de Informatica y Sistemas Edif. de Informatica y Matematicas. Campus Universitario de Tafira. 35017. Las Palmas. Spain. E-mail: mafonso@dis.ulpgc.es, cguerra@iusiani.ulpgc.es mhernandez@iusiani.ulpgc.es

Received: November 30, 2007 

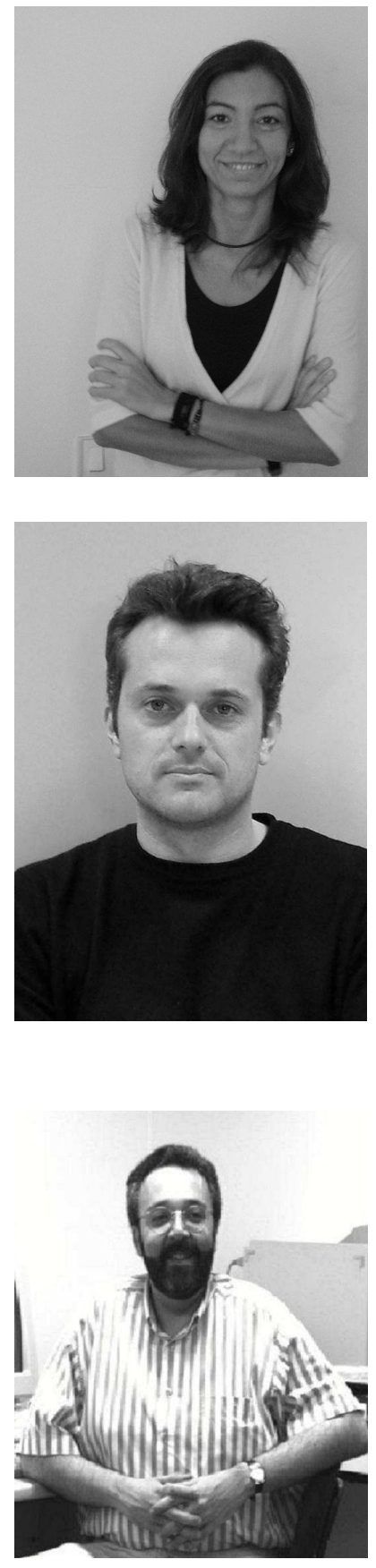

Maria Dolores Afonso Suarez, graduated at the University of Las Palmas de Gran Canaria in Computer Science. She has worked in private enterprises developing software and as associated professor at the Computer Science and Systems Department of the University of Las Palmas de Gran Canaria. Her main research fields are Multimedia and e-Learning.

Cayetano Guerra Artal, graduated at the University of Las Palmas de Gran Canaria in Computer Science. He has been teaching Multimedia for seven years at the Computer Science and Systems Department of the University of Las Palmas de Gran Canaria. He received his Ph.D. in Computer Vision. His main research fields are Computer Vision, Computer Graphics, Multimedia and e-Learning.

Francisco Mario Hernandez Tejera graduated in Electrical Engineering and received his Ph.D. in Computer Science at the University of Las Palmas of Gran Canaria. He is Assistant Professor of Computer Science and Engineering at the Computer Science and Systems Department of the University of Las Palmas de Gran Canaria. Is member of the Institute of Electrical and Electronic Engineers IEEE , the International Association of Pattern Recognition (IAPR), the Asociacion Española de Reconocimiento de Formas y Analisis de Imgenes (AERFAI) and the Asociacion Española para la Inteligencia Artificial (AEPIA). His current research interests are in Autonomous Systems, Knowledge-Based Systems, Active Vision, Visual Learning, Scene Analysis, Mobile Robotics and Interactive Robotic Systems, that is robots that interact with people. As well as Multimedia and e-Learning. 